\title{
Radiological Anatomy - Evaluation of Integrative Education in Radiology
}

\author{
Anatomie im Röntgenbild - Evaluation der integrativen Lehre in der Radiologie
}

Authors

Affiliations
S. Dettmer ${ }^{1}$, A. SchmiedI ${ }^{2}$, S. Meyer ${ }^{1}$, A. Giesemann ${ }^{3}$, R. Pabst ${ }^{4}$, J. Weidemann ${ }^{1}$, F. K. Wacker ${ }^{1}$, T. Kirchhoff'

Institute for Diagnostic and Interventional Radiology, Hannover Medical School, Germany

Institute for Functional and Applied Anatomy, Hannover Medical School, Germany

Institute for Diagnostic and Interventional Neuroradiology, Hannover Medical School, Germany

${ }^{4}$ Institute for Immunmorphology, Hannover Medical School, Germany
Key words

- anatomy education

- diagnostic imaging utilization

- undergraduate education

- medical Schools

eingereicht 29.8 .2012

akzeptiert 18.3.2013

Bibliography

DOI http://dx.doi.org/

10.1055/s-0033-1335048

Published online: 25.7.2013

Fortschr Röntgenstr 2013; 185 :

838-843 @ Georg Thieme

Verlag KG Stuttgart · New York .

ISSN 1438-9029

\section{Correspondence \\ Dr. Sabine Dettmer}

Institute for Diagnostic and Interventional Radiology,

Hannover Medical School-

Germany

Carl-Neuberg-Str. 1

30625 Hannove

Germany

Tel.: ++49/5 11/5323421

Fax: ++49/511/5329421

sabine-dettmer@t-online.de

\section{Abstract}

\section{$\nabla$}

Purpose: Evaluation and analysis of the integrative course "Radiological Anatomy" established since 2007 at the Medical School Hannover (MHH) in comparison with conventional education.

Materials and Methods: Anatomy and radiology are usually taught separately with a considerable time lag. Interdisciplinary teaching of these associated subjects seems logical for several reasons. Therefore, the integrative course "Radiological Anatomy" was established in the second year of medical education, combining these two closely related subjects. This interdisciplinary course was retrospectively evaluated by consideration of a student questionnaire and staff observations. The advantages and disadvantages of integrative teaching in medical education are discussed.

Results: The course ratings were excellent (median 1 ; mean 1.3 on a scale of 1 to 6 ). This is significantly $(\mathrm{p}<0.001)$ better than the average of all evaluated courses in the respective term (grade 2.8 ). The course improved the anatomical comprehension (90\%) and the students stated that the topics were relevant for their future medical education (90\%). Furthermore, interest in the subject's anatomy and radiology increased during the course ( $88 \%)$. According to the students' suggestions the course was enhanced by a visitation in the Department of Radiology and the additional topic central nervous system.

Conclusion: Integrative teaching of anatomy and radiology was well received by the students. Both, anatomical and radiological comprehension and the motivation to learn were improved. However, it should be considered, that the amount of work and time required by the teaching staff is considerably increased compared to traditional teaching.

Key Points:

- Combined teaching of anatomy and radiology may improve anatomical and radiological comprehension.

- Integrative teaching enhances the students' motivation to learn and their interest in the subjects.

- The students' ratings of our integrative course was better than those of conventional courses.

Citation Format:

- Dettmer S, Schmiedl A, Meyer S et al. Radiological Anatomy - Evaluation of Integrative Education in Radiology. Fortschr Röntgenstr 2013; 185: $838-843$

\section{Zusammenfassung}

Ziel: Die Evaluation und Analyse des integrativen Faches „Anatomie im Röntgenbild“, das seit 2007 an der Medizinischen Hochschule Hannover (MHH) etabliert ist, im Vergleich zu herkömmlichen Kursen.

Material und Methoden: Anatomie und Radiologie werden meist unabhängig voneinander und mit zeitlicher Trennung unterrichtet, obwohl ein gemeinsamer Unterricht sinnvoll erscheint. Deshalb wurde das vorklinische integrative Wahlpflichtfach „Anatomie im Röntgenbild“ etabliert. Es werden die studentische Evaluationen sowie die Beobachtungen der Dozenten bezüglich des Lernverhaltens der Studierenden retrospektiv analysiert und basierend darauf die Vor- und Nachteile der integrativen Lehre in der medizinischen Ausbildung diskutiert.

Ergebnisse: Die Studierenden bewerteten den Kurs mit „sehr gut“ (Median: 1; Mittelwert 1,3; auf einer Skala von 1 -6). Diese Bewertung war somit signifikant $(p<0,001)$ besser als die durch- 
schnittliche Bewertung aller evaluierten Kurse im 2. Studienjahr (Note 2,8). Die Studierenden gaben an, dass der gemeinsame Unterricht das anatomische Verständnis erleichtert (90\%) und dass das Gelernte Relevanz für ihre zukünftige Tätigkeit hat (93\%). Der Kurs hat das Interesse der Studierenden an den beiden Fächern verstärkt (88\%). Dem Wunsch nach einer Ausweitung des Kurses wurde durch das Angebot einer Besichtigung der Radiologie und der Einführung des zusätzlichen Kurstags „Zentrales Nervensystem“ Rechnung getragen, was von den Studierenden positiv bewertet wurde.

Schlussfolgerung: Die integrative Lehre von Anatomie und Radiologie erwies sich als ein Lehrkonzept mit großer Akzeptanz bei den Studierenden. Sie verbesserte das anatomische und auch das radiologische Verständnis und erhöhte die Lernmotivation. Es sollte allerdings beachtet werden, dass sich der Zeitaufwand für die Dozenten im Vergleich zum herkömmlichen Unterricht erheblich erhöht.

\section{Introduction}

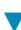

Anatomy, like other foundational subjects in medicine, is a traditional part of the pre-clinical training at medical schools in Germany and abroad [1]. The time lag between the teaching of this fundamental knowledge and its application in corresponding clinical application is between two and three years in the normal course of the study of human medicine. During this time, the content of the foundational courses is partially forgotten. Further, students generally do not recognize the clinical relevance of the knowledge gained during the pre-clinical phase of their studies. Due to this issue, medical faculties are increasingly offering integrative courses, either as part of a model course of study, such as at MHH, or during the normal program; such courses teach basic anatomical, physiological and biochemical concepts, either in part or in whole with related clinical subject matter. The goal of this new curriculum is the integration of foundational and clinical courses in problem-oriented learning that focuses on essential content instead of detailed knowledge as well as promoting improvement of communication skills and joint and independent study [2]. Although this trend has been observed mainly in the last decade, the advantages of integrative teaching were discussed over 25 years ago [3]. It was demonstrated that combining fundamental and applied anatomy with "living anatomy", radiological anatomy and clinical patient presentation significantly increased the interest of students in gross anatomy [3]. These innovative course offerings should be constantly evaluated and the results published [4], so that other medical schools will be encouraged to implement new instructional methods. In addition, the evaluation of instruction is significant for further development as well as assessment of performance-related funding.

Integrative teaching can be an essential component particularly for radiology [5], first, in connection with clinical subjects in which imaging plays an important role, such as surgery and internal medicine, second, in relation to the teaching of anatomy. New radiological methods such as multiplanar modeling, virtual endoscopy, functional and molecular imaging or spectroscopy currently provide numerous options for including radiological subject matter into the teaching of foundation courses [6]. Knowledge acquired in fundamental courses is the prerequisite for material to be learned later in clinical subjects, including anatomical knowledge for surgery [7, 8] and radiology $[5,9]$. The licensing regulations for physicians require two elective subjects in human medicine, one in the first two years of study and an additional course in the following three years of study [10].

This study will discuss the evaluations performed over time by students in the pre-clinical elective "Radiological Anatomy" and assess the courses from their point of view.

\section{Materials and Methods \\ $\nabla$}

Since 2007, the anatomical-radiological elective "Radiological Anatomy" has been offered at MHH. This pre-clinical course covers 28 hours and takes place in the second year of study after the students have already completed the course in gross anatomy in their first year, but not have yet had instruction in radiology. This is a pre-clinical elective course (WPF) with attendance and performance monitoring, that is, the students must select a course from a selection of various class offerings. When selecting a class, the students use a priority list $(1-5)$ to indicate which elective they would like to take. If, as their first choice, several students have selected a particular elective with greater demand than openings, students are selected by lottery. Then lower priority course selections are considered. The course instructors or other criteria such as previous grades have no influence on the allotment of places. Initially, the size of the group in the elective course was 16 students; this was later limited to a maximum of 12 students per course.

The objective of this course is to apply students' previous anatomical knowledge to the interpretation of radiological images, thus making the subject matter of X-ray imaging and computer tomography more accessible. Moreover, the relevance of anatomy is emphasized, and topographical understanding of the body is improved. The topics covered are the thorax, skeleton, large vessels and, since 2011, the central nervous system.

At the start of the course, students receive a brief theoretical introduction to the functionality of the standard X-ray procedure and computer tomography (CT). In addition, the related gross anatomy is summarized using an anatomical tissue sample. Subsequent small group work comprises the greatest time component of the course. Groups of three students consider clinical-radiological cases. The required $\mathrm{X}$-ray images are provided as high-quality printouts, and the CT images are displayed as QuickTime movies on laptops. Anatomical wet preparations, skeletons, anatomical models and atlases are available for anatomical orientation. At the end of every class, the cases considered are discussed and analyzed by all participants, with the individual groups presenting their respective cases.

The following uses the class on the thorax as an illustration of the concept. First, a normal finding of a thoracic examination using X-ray is shown. The students should be able to locate anatomical structures and learn how to orient themselves in a projected image. Following this is the assessment of X-ray images with pathological changes selected to improve anatomical understanding. For example, pneumonia should be identified in the correct lobe of the lung. Addi- 


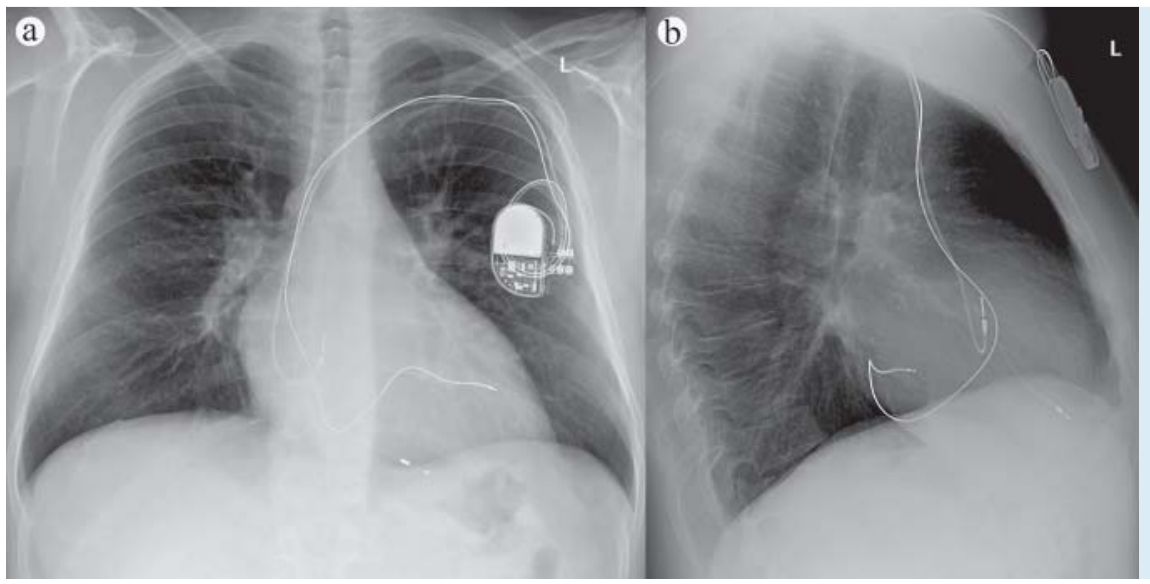

Fig. 1 Posterior-anterior $\mathbf{a}$ and lateral $\mathbf{b}$ thoracic $\mathrm{X}$-ray of a patient. Using a model heart, many students could properly locate the pacemaker probes in the right auricle, right ventricle and coronary sinus.

tional tasks include proper localization of the probes of a biventricular pacemaker ( $\bullet$ Fig. 1 ) or central venous catheters (CVC) in both typical and incorrect position. Further, mediastinal space requirements should be matched to the frontal, medial or rear mediastinum as a basis for a discussion of which structures could be affected due to their anatomical position. Using a pleural effusion and a postoperative pneumopericardium, the students become familiar with the thoracic cavities. The cases presented are selected to permit the students to use their anatomical knowledge to solve the illustrated problems. Although clinical issues remain in the background, they are elucidated as necessary. During the entire course, one instructor each from the Anatomy and Radiology departments are present to support the students while they work on the cases and answer any related questions.

At the conclusion of the entire course, the students' knowledge is tested by a written exam using essay questions and radiological images. Grading is based on work during the individual classes and the results of a proctored written examination.

On the last day of the course, an anonymous written evaluation is performed in which the students rate the course on a scale of 1 to 6; they can also indicate which parts of the course they liked or did not like, as well as provide suggestions for improvement. They are also asked whether including radiology had aided their understanding of anatomy, whether they feel that the knowledge gained could be relevant for the future, and whether the course had increased their interest in anatomy and radiology.

The extensive assessment was performed retrospectively after the course was offered eight times and based on student evaluations as well as appraisal by the instructors of the students' work and learning behavior. Grading of the elective course by the students during the evaluation was non-parametrically assessed using descriptive statistics and the Mann-Whitney-U-Test (IBM SPSS Statistics, Ver. 20, San Jose, USA). Grading of the elective course by the students was also compared to the grades given to the required courses in the second year of study. Since the elective course was graded on a 1-6 scale and the other courses were evaluated on a 1-15 scale, conversion used the following formula: points $=(17$ points $) / 3)$. A multi-course comparison of all current elective course evaluations in the same phase of study could not be performed since not all courses were evaluated. Homogeneity of random samples (before/after change of group size and before/after introduction of the CNS class) was previously determined using a chi-square homogeneity test. The results of the written examinations in the later mandatory radiology course (fifth year) of those students who had taken the elective course and those who had not were compared using the Mann-Whitney-U-Test. The level of significance for the tests was 0.05 .

\section{Results}

$\nabla$

Acceptance of the elective course and learning atmosphere was exceptionally good. The working relationship in the small groups was intensive and focused on radiological images and anatomical atlases. In particular, the students independently relied on the wet anatomical preparations and models when faced with difficult tasks. The help provided by the instructional staff from Radiology and Anatomy was willingly accepted by the students even with respect to discussions of clinical issues or working in the Radiology department.

Initially, the maximum number of participants was 16 students. During the course it was clear that small groups working on X-ray and CT images required intensive guidance. Therefore group size in subsequent semesters was limited to 12 students.

In total, 82 student questionnaires were assessed, with a return rate of $>95 \%$. The results of this evaluation are shown in 1 Fig. 2. On the whole, the elective course was awarded the grade 1 ("very good", on a scale of $1-6$; median 1 , average value 1.3 ; minimum: 1 , maximum: 3 ). Almost all students (90\%) were in agreement that including radiology made understanding anatomy easier. They based this on enhanced topographical understanding and new perspectives gained by working with radiological images. They also indicated that the relevance of anatomy was made clearer. Only a few students ( $9 \%$ ) were doubtful in this regard; one stated that understanding of radiology could have been improved. Another replied in the negative without further explanation. $93 \%$ of the students were in agreement that the newly acquired knowledge was relevant to their future, mainly 

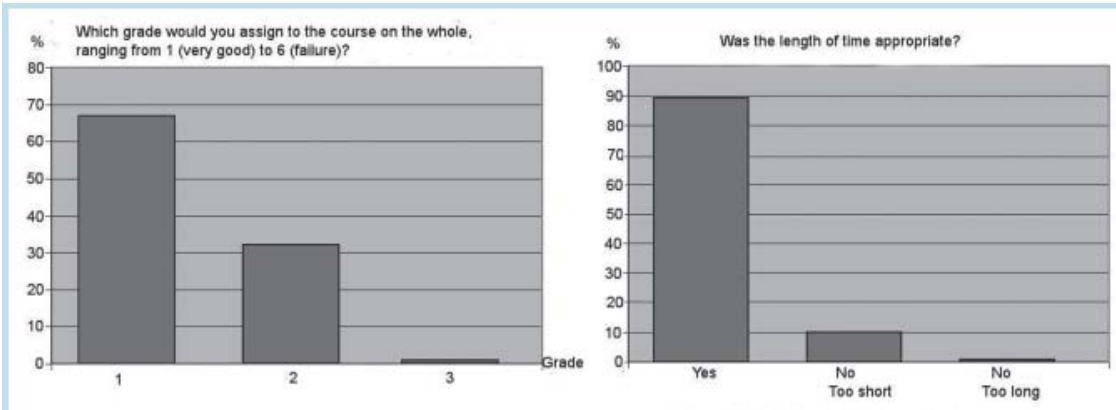

Fig. 2 Bar graphs representing an overview of evaluation results, $\mathrm{n}=82$.

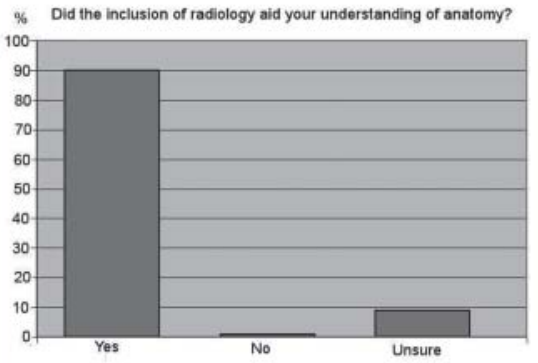

knowedge acquired here

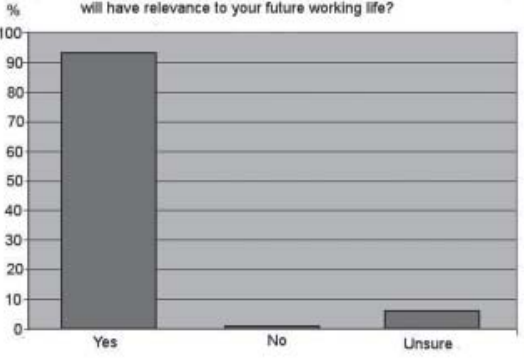

Did the course increase your interest in the subject matter?
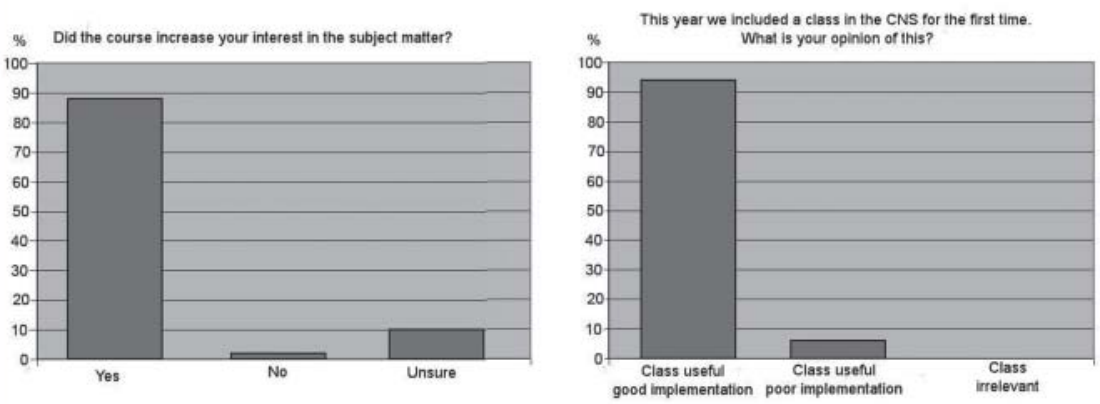

due to the application of radiological examination methods to solving problems in almost all fields of medicine. In addition, the course removed trepidations regarding hands-on work. $6 \%$ were unsure about this issue without providing any reason for this. One student ( $1 \%$ ) provided a negative response, claiming that $\mathrm{CT}$ images themselves were too complex. $88 \%$ of the students felt that the elective course increased their interest in anatomy and radiology primarily because they had access to radiology and developed increased understanding of X-ray images. $10 \%$ were unsure in this regard, and $2 \%$ replied in the negative, one of whom indicated that his interest had already been great prior to the course. For $89 \%$ of the students the time frame was appropriate; $10 \%$ would have preferred an expansion of the course, and only one student (1\%) thought that the course, particularly the small group work, was too drawn-out.

In the open-ended questions regarding the advantages and disadvantages of the course and potential improvements, the students positively emphasized independent work on $\mathrm{X}$-ray images and interesting cases as well as clinical relevance. In addition, good support and detailed explanations by the instructors, small group size and sufficient time for handling images were frequently praised. The main criticism concerned the scheduling of the course, as it was held on Friday afternoons; unfortunately due to organizational reasons, that could not be changed. Suggestions for improvement mainly concerned expanding the course to include the central nervous system (CNS); this was proposed several times. There were also suggestions to add the spinal column and sex organs (each mentioned twice) as well as to expand the course to include including magnetic resonance imaging (MRI). Further, there was a desire to visit the Radiology department.

As a result of these suggestions, the students were offered the opportunity to visit the Radiological Institute at $\mathrm{MHH}$ with a short guided tour of the department. The students positively responded to this in the open-ended part of the evaluation. Furthermore, the number of students in each course was reduced from a maximum of 16 to 12 in that same academic year (starting winter semester 2009/10). This did not result in any significant change in the student evaluations; prior to the size reduction, the average course grade was 1.36 (median 1.0) $(n=43)$ and afterward the average was 1.33 (median 1.0, $\mathrm{n}=39$ ). In their evaluations, the students considered the additional class day devoted to the CNS starting in the winter semester 2011 to be an improvement $(n=15)$. After the introduction of this class, the overall grade given increased from an average of 1.4 (median 1.0 ) to 1.1 (median 1.0 ), on a scale of $1-6$ ). The chisquare homogeneity test did not indicate any heterogeneity resulting from the change in group size $(p=0.570)$ and introduction of the additional CNS class $(p=0.112)$; consequently the groups were consolidated for additional analysis.

The integrative elective course, graded 1 (median) and 1.3 (average value) in the evaluation by the students $(n=82)$, 
did significantly better $(\mathrm{p}<0.0001)$ than the other required courses in the same year of study $(n=4322)$. The average grade given by the second-year students during the period 2007 - 2012 was 10 points (median) and 8.67 points (average) on a scale of $1-15$. Converted, this corresponds to a grade of 2.3 (median) and 2.8 (average), based on the formula (17 points)/3).

Of the students participating in the elective course, 31 have already passed the radiology written examination (5th year of study). For the students who had taken the elective course during the pre-clinical phase, the average grade on the radiological examination $(1.58, \mathrm{n}=31)$ was somewhat better than those who had not participated $(1.73, \mathrm{n}=365)$. Statistically, this was not significant $(p=0.320)$.

\section{Discussion}

$\nabla$

Our results show that integrative teaching of anatomy and radiology is a useful enhancement of the traditional preparatory course in anatomy which can improve the student's learning process as well as supplement anatomical and radiological content of coursework. The evaluations make it clear that students judged the integrative course "Radiological Anatomy" to be superior to other courses at this point in their studies. Students who had taken this elective performed somewhat better later on the radiological examination than those who had not taken the elective. The result for those few students who have currently completed their examination is not significant. It remains to be seen whether this positive trend will continue in the future. The fact that the participants in our elective course performed somewhat better on the radiology examination might also rely on the still limited size of the sample group $(n=31)$. It is conceivable that interest in radiology and related preparatory training may lend a bias. It would be an interesting supplement to the study to query former course participants at the end of their medical studies regarding the influence the elective had on their work and selection of specialty, once a related number of participants had reached this level of training.

Foundational knowledge of anatomy is without a doubt an important prerequisite for the interpretation of all modalities of radiological images; normal anatomy must be identified before pathological changes can be observed. By implementing radiology relatively early into medical studies, and linking it to anatomy, foundational knowledge is available during radiological training, or can be easily taught as needed.

Conversely, the integration of clinically-relevant material from radiology can facilitate the understanding of anatomy [11]. This especially relates to topographical anatomy. The ability of the students to think in three dimensions was improved not only by studying tissue samples, but also by means of projected images, cross-sections and three-dimensional reconstructions; consequently the image of the human body was steadily improved. Although anatomical structures are frequently easily identifiable in samples, it is more difficult to do this in an X-ray image, as it requires more exact topographical knowledge. The inclusion of radiology makes the students aware of shortcomings in their anatomical knowledge, and what is clinically relevant.
The results of the evaluations made it clear that topography in particular is gaining in importance. When studying anatomy on their own, many students learn unimportant details by heart; as a result of integrative teaching they become increasingly capable of identifying important knowledge and consequently focus on essentials. Recognizing that anatomical knowledge has direct relevance for clinical application reinforces the student's motivation to learn anatomy. This has already been indicated in earlier reports regarding the joint teaching of gross anatomy, clinical material and radiological imaging $[11,12]$; it has also been presented as a teaching concept in various anatomical textbooks $[13,14]$.

In contrast to Unsull et al. [15] who, using a cross-sectional student questionnaire, indicated that radiological methods were usually not used by students to learn anatomy, we were able to demonstrate that students have intensively used conventional X-ray images and CT data sets to improve their understanding of anatomy, if these were provided within an appropriate framework. This may also have to do with the ability of the students to connect new examination methods with clinical relevance.

The integrative course we offered was presented after the course in gross anatomy. Based on this traditional preparatory course, the students had a good fundamental knowledge of anatomy. We are of the opinion that this basic knowledge is an essential and important foundation for subsequent integrative teaching. Only thus can the student tie in existing knowledge and apply it in a clinical context. Likewise, Hindura et al., when comparing a conventional preparatory course with a purely integrative one, discovered that integrative learning alone is less efficient $[16,17]$. Integrative learning can supplement, but not replace the preparatory course [18]. In this respect we are also in agreement with Evans and Watt [19] who promote the idea that a good medical education requires the proper combination of basic learning and clinical knowledge.

Despite the apparent advantages of integrative teaching in training students, the time factor for the instructors must be critically examined. Integrative teaching requires intensive support of the students in size-restricted groups and can be implemented to a limited extent for organizational reasons. A less time-consuming alternative for the instructional staff using integrative teaching of anatomy would be a web-based lecture or collection of cases. Examples of this are the lecture series presented by Marker et al. [20] containing radiological images to be worked on by students in parallel to the topics of the preparatory course; the Internet-based training program for radiology by Grunewald et al. [21] as well the application of Ilias in radiology published by Schütze et al. [22]. Since instructors do not need to be present when this instructional method is used, their time commitment is reduced once the online course has been made available. However, discussion between the student and instructor, highly valued by students, is not possible. This interaction was mentioned in the evaluation results; the intensive support provided by instructors and their detailed explanations were positively emphasized. In a direct comparison between an interactive tutorial and computerassisted instruction, the tutorial was preferred [23]. Another option would be the combination of a course on radiological anatomy with an accompanying collection of 
cases for self-study, similar to what was practiced at the University of Florida 20 years ago [24]. This type of course, requiring substantially less time commitment than our course, was viewed very positively by the students.

Evaluation of teaching has increased in importance. Nowadays it plays not only a role in the development of instructional methods, it is increasingly influential in determining performance-based funding.

Regarding radiology, course offerings should also consider that if this elective is introduced early in medical studies, it will make students aware of the subject. This will have positive effects by potentially motivating students to continue in this field, as there are currently problems attracting students to radiology.

In summary, our results show that integrative teaching of anatomy and radiology is a useful enhancement of the traditional preparatory course in anatomy which can improve the student's learning process as well as supplement anatomical and radiological content of coursework. On the one hand, integrative teaching can provide students with new perspectives on anatomy and aid in developing improved topographical visualization capabilities; on the other hand, this teaching method can make students more sensitive to clinically-relevant anatomical knowledge while giving them their first insight into radiological techniques. However, integrative courses cannot replace conventional courses, since necessary basic understanding must be gained in advance. It should also be kept in mind that due to size limitations of the groups and relatively time-intensive support by instructors in radiology and anatomy, only a limited quota of medical students can participate in the integrative course.

\section{Acknowledgments}

We would like to thank Mr. Werner Kohne, Mrs. Gabriele Ulrich and Mrs. Marita Peter for its support during the course. Further, we thank Dr. Volkhard Fischer for kindly providing the results of the evaluations of the second year class and Dr. Michael Schneider and Dr. Anika Großhennig for the statistical guidance during the assessment.

\section{Acknowledgement}

$\nabla$

This manuscript is dedicated to Professor Bernd Hamm for his 60th birthday.

\section{References}

1 Turney BW. Anatomy in a modern medical curriculum. Ann R Coll Surg Engl 2007; 89: 104-107

2 Azer SA, Eizenberg $N$. Do we need dissection in an integrated problembased learning medical course? Perceptions of first- and second-year students. Surg Radiol Anat 2007; 29: 173-180

3 Pabst R, Westermann J, Lippert $H$. Integration of clinical problems in teaching gross anatomy: living anatomy, X-ray anatomy, patient presentations, and films depicting clinical problems. Anat Rec 1986; 215: $92-94$

4 Pabst R. Anatomy curriculum for medical students. What can be learned for future curricula from evaluations and questionnaires completed by students, anatomists and clinicians in different countries? Ann Anat 2009; 191: 541 - 546

5 Zumwalt AC, Lufler RS, Monteiro J et al. Building the body: active learning laboratories that emphasize practical aspects of anatomy and integration with radiology. Anat Sci Educ 2010; 3: 134-140

6 Miles KA. Diagnostic imaging in undergraduate medical education: an expanding role. Clin Radiol 2005; 60: $742-745$

7 Peuker ET, Filler TJ, Berns T et al. Klinische Anatomie als integrierendes Element in der Lehre der operativen Fächer. Chirurg 1998; 69: 1324 1328

8 Older J. Anatomy: a must for teaching the next generation. Surgeon 2004; $2: 79-90$

9 Chowdhury R, Wilson ID, Oeppen RS. The departments of radiology and anatomy: new symbiotic relations? Clin Radiol 2008; 63: 918-920

10 Bundesrat. Approbationsordnung für Ärzte (ÄAppO). Bundesanzeiger; 2002

11 Boon JM, Meiring JH, Richards PA et al. Evaluation of clinical relevance of problem-oriented teaching in undergraduate anatomy at the University of Pretoria. Surg Radiol Anat 2001; 23: 57-60

12 Dettmer S, Tschernig T, Galanski $M$ et al. Teaching surgery, radiology and anatomy together: the mix enhances motivation and comprehension. Surg Radiol Anat 2010; 32: 791 - 795

13 Lippert H, Herbold D, Lippert-Burmester W. Anatomie am Krankenbett: Körperliche Untersuchung und kleine Eingriffe. Berlin, Heildelberg: Springer; 1997

14 Lippert H. Lehrbuch Anatomie. München: Urban \& Fischer; 2011

15 Insull PJ, Kejriwal R, Blyth P. Surgical inclination and anatomy teaching at the University of Auckland. ANZ J Surg 2006; 76: 1056-1059

16 Gunderman RB, Wilson PK. Viewpoint: exploring the human interior: the roles of cadaver dissection and radiologic imaging in teaching anatomy. Acad Med 2005; 80: 745-749

17 Hinduja K, Samuel R, Mitchell S. Problem-based learning: is anatomy a casualty? Surgeon 2005; 3: 84-87

18 Winkelmann A. Anatomical dissection as a teaching method in medical school: a review of the evidence. Med Educ 2007; 41: $15-22$

19 Evans DJ, Watt DJ. Provision of anatomical teaching in a new British medical school: getting the right mix. Anat Rec B New Anat 2005; 284: $22-27$

20 Marker DR, Bansal AK, Juluru K et al. Developing a radiology-based teaching approach for gross anatomy in the digital era. Acad Radiol 2010; 17: $1057-1065$

21 Grunewald M, Heckemann RA, Gebhard $H$ et al. COMPARE radiology: creating an interactive Web-based training program for radiology with multimedia authoring software. Acad Radiol 2003; 10: 543-553

22 Schütze B, Mildenberger P, Kämmerer M. E-learning in der Radiologie praktischer Einsatz des Content-Management-Systems Ilias. Fortschr Röntgenstr 2006; 178: 525-530

23 Liebermann $G$, Abramson $R$, Volkan $K$ et al. Tutor versus computer: a prospective comparison of interactive tutorial and computer-assisted instruction in radiology education. Acad Radiol 2002; 9: 40-49

24 Lanier L, Kaude JV. Radiologic anatomy - a credit course for first-year medical students. Acta Radiol 1993; 34: 414-416 